\title{
CARL SCHMITT E LEO STRAUSS: DIÁLOGO ENTRE CONSERVADORES PARA ALÉM DO LIBERALISMO?
}

\author{
Deyvison Rodrigues Lima ${ }^{1}$ \\ Universidade Federal do Rio de Janeiro (UFRJ) \\ (D) https://orcid.org/0000-0002-7879-8388
}

\begin{abstract}
RESUMO:
$\mathrm{O}$ artigo aborda a interpretação de Leo Strauss sobre o "O conceito do político" de Carl Schmitt no texto "Notas sobre Carl Schmitt, O conceito do Político". Tem por objetivo analisar os argumentos de Strauss contra Schmitt e seus comentários sobre o liberalismo. As críticas de Strauss são expostas em alguns argumentos centrais e, a partir deles, pretende-se elaborar uma reinterpretação do texto de Schmitt: a tese de que o jurista possui no texto sobre o político um realismo vinculado à imanência, mais precisamente, à relação de conflito como originária da ordem. Esta pode ser descrita como uma postura monista ou finitista em teoria política. Como conclusão, ressalta-se o abandono da Veritas transcendente para a validade da ordem política e a diferença entre os autores na possibilidade de uma política pós-liberal.
\end{abstract}

PALAVRAS-CHAVE: Liberalismo; Político; Natureza; Conflito; Pósliberalismo.

\section{CARL SCHMITT E LEO STRAUSS: DIALOGUE BETWEEN CONSERVATIVES BEYOND LIBERALISM?}

\begin{abstract}
:
The article discusses the interpretation of Leo Strauss on "The concept of the political" of Carl Schmitt in the text "Notes on Carl Schmitt, The Concept of the Political." It aims to analyze the arguments against Schmitt and his comments on liberalism. Strauss's criticisms are exposed in some central arguments and, from them, we intend to draw up a Schmitt text reinterpretation: the thesis that the lawyer has a political realism linked to immanence, more precisely, the conflict relationship as originating the
\end{abstract}

\footnotetext{
${ }^{1}$ Doutorando em Filosofia pela Universidade Federal do Rio de Janeiro (UFRJ), Rio de Janeiro - Brasil. Bolsista CAPES. E-mail: deyvisonrodrigues@ yahoo.com.br.
} 
order. This approach can be described as a monistic thesis in political theory. In conclusion, we emphasize the abandonment of transcendent Veritas to the validity of the political order and the difference between the authors of the possibility of a post-liberal policy.

KEYWORDS: Liberalism; Political; Nature; Conflict; Post-Liberalism.

No texto Anmerkungen zu Carl Schmitt, Der Begriff des Politischen (Notas sobre "O conceito do político" de Carl Schmitt) de $1932^{2}$, Leo Strauss assume, por um lado, o ponto de partida do jurista alemão quanto às críticas ao liberalismo; por outro, elabora comentários acerca dos motivos, limites e contradições do texto schmittiano ${ }^{3}$. Segundo Strauss, o texto schmittiano seria um libelo moral contra a despolitização provocada pelo liberalismo. No entanto, ao mesmo tempo em que elogia a estratégia não liberal e a crítica à técnica, Strauss sustenta que Schmitt possui uma argumentação contraditória: ao expor o fracasso da hegemonia liberal e normativista, a descentralização do poder do Estado, a despolitização e neutralização em marcha na modernidade, Schmitt aposta nas teses de Hobbes e, por isso, cai em contradição, pois tece uma argumentação contra o liberalismo lançando mão do fundador do liberalismo. Ele não teria percebido que Hobbes é, na própria acepção do Politischen como conflito, o antipolítico por excelência, isto é, aquele que na construção do Estado moderno oblitera a relação e o conflito através da instituição jurídica e, afinal, promove a instauração do mundo liberal. Durante os comentários, Strauss reforça o tema central da sua trama com Schmitt contra o liberalismo, "uma crítica radical ao liberalismo é possível apenas com base numa compreensão adequada de Hobbes" (STRAUSS, 2007, p. 122). A contradição que o autor aponta no jurista, porém, refere-se

\footnotetext{
${ }^{2} \mathrm{O}$ texto de Leo Strauss consultado está presente na edição americana do livro de Carl Schmitt (The Concept of the Political. Chicago: University of Chicago Press, 2007), com tradução de Georg Schwab da $2^{a}$ edição do Der Begriff des Politischen de 1932. Nesta edição, além do texto principal sobre o político, constam o The Age of Neutralizations and Depoliticizations de 1929 [Das Zeitalter der Neutralisierung und Entpolitisierungen], tradução de Matthias Konzen e John McCormick, e os referidos comentários de Strauss, traduzidos por J. Harvey Lomaz como Notes on Carl Schmitt, The Concept of the Political, publicado originalmente como Anmerkungen zu Carl Schmitt, Der Begriff des Politischen, in Archiv für Sozialwissenschaft und Sozialpolitik (Tübingen), LXVII, no 6, 1932, p. 732749 , texto enviado alguns anos antes para o jurista.

${ }^{3}$ A $1^{\text {a }}$ edição do Der Begriff des Politischen foi publicada no Archiv für Sozialwissenschaft und Sozialpolitik, LVIII, 1927, $\mathrm{n}^{\mathrm{o}}$ 1, p.1-33; a $2^{\mathrm{a}}$ edição aparece em 1932, com alterações importantes e acompanhado pelo Das Zeitalter der Neutralisierungen und Entpolitisierungen (Munique: Duncker \& Humblot). A $3^{\text {a }}$ edição, com modificações contextuais (Hamburgo: Hanseatische Verlagsanstalt) e a de 1963, edição que utilizamos publicada pela Duncker \& Humblot: Berlim - Text von 1932 mit einem Vorwort unf drei Corollarien. Na versão de 1932, conforme a leitura de H. Meier (2006) estariam presentes as considerações das notas de Strauss.
} 
ao equívoco do argumento hobbesiano da soberania do Estado utilizado por ele contra o liberalismo e os processos de despolitização e neutralização compreendidos seja como uma descentralização da autoridade estatal ou substituição do soberano por uma ordem ou fonte de produção mecânica de normas técnicas, seja como uma desestatização ou deslocamento da instância da decisão e da autoridade do Estado e autonomização de instância sociais. Assim, Schmitt não teria percebido que utiliza o autor responsável pelo liberalismo para criticar o liberalismo, numa circularidade que enfraquece sua tese e constitui o mais perspicaz argumento do texto straussiano $^{4}$. Não à toa, no início da década de 1930, Schmitt percebe as limitações de uma filiação hobbesiana e rejeita o argumento decisionista, além de descrever, no final da década, como Hobbes desencadeou o processo de racionalização burocrática que culminou na neutralização do político, reduzido a puro mecanismo administrativo e impessoal.

A análise de Strauss sobre o ataque schmittiano contra o liberalismo prossegue ainda em relação ao Das Zeitalter der Neutralisierungen und Entpolitisierungen (A era das neutralizações e despolitizações), palestra de 1929 anexada à $2^{\text {a }}$ edição do Der Begriff des Politischen (O conceito do Político) em 1932 que constitui uma continuação ou variação sobre o tema da crítica ao liberalismo e diagnóstico da época. Demonstra uma estratégia de despolitização e neutralização em curso por alguns séculos não como um efeito colateral, mas sim como fim ou meta (Ziel) do liberalismo. Neste contexto, o destino liberal estaria marcado desde o início da modernidade, mais precisamente, desde o mundo seiscentista, novamente, com Hobbes, o "autor do ideal de civilização" que luta contra a "natureza não liberal do homem" (STRAUSS, 2007, p. 107).

\footnotetext{
${ }^{4}$ H. Meier (2006) é responsável por uma leitura coerente sobre a relação entre Strauss e Schmitt. Retoma a relação oblíqua entre o jurista de renome e o jovem filósofo conservador a partir da análise respeitosa, porém crítica no texto das Anmerkungen: a indicação de Schmitt para uma bolsa da fundação Rockfeller em Paris, o elogio de Schmitt e proposta para a publicação das Anmerkungen no mesmo periódico onde anos antes fora publicado a $1^{\text {a }}$ versão do Der Begriff des Politischen, bem como as cartas de um devoto Strauss e sua admiração e reconhecimento. $\mathrm{O}$ argumento principal de Meier é se refere às alterações que Schmitt realizara em seus textos a partir das críticas straussianas, sobretudo, a análise das sugestões e críticas ao texto de 1927 assumidas por Schmitt na $2^{a}$ edição em 1932, por exemplo, no distanciamento do conceito do político dos âmbitos da cultura para considerálo como grau de intensidade, o que marca uma mudança de estratégia do jurista que deixaria de analisar uma instância social para uma ontologia na qual relação e não substância teria primazia. Além disso, a compreensão sobre Hobbes que em 1927 era descrito como "de longe, o maior e talvez único pensador político" para, em 1932, "verdadeiramente, um pensador político moderno e sistemático" (SCHMITT, 2002, p. 64). Entretanto, a interação entre ou autores atende a uma história mais longa e intricada: podese citar, por exemplo, o livro de 1934 Über die drei Arten des rechtswissenschaftlichen Denkens como crítica ao pensamento decisionista de Thomas Hobbes e guinada em direção ao pensamento da ordem que Strauss atribui à reação/assimilação de sua leitura por parte de Schmitt e o livro de 1938 Der Leviathan in de Staatslehre des Thomas Hobbes como resposta não apenas à Walter Benjamin, mas também para Strauss.
} 
Entretanto, para Strauss, apesar de partilhar o diagnóstico schmittiano, há outra falha nas investigações do jurista, na verdade, ligada à inicial, qual seja, na acertada contraposição ao liberalismo, Schmitt não apenas se equivoca ao utilizar o liberal Hobbes contra o liberalismo como também o conceito do político continuaria no interior do liberalismo já que não se desvincula da instância concreta ou dos âmbitos culturais e históricos ao invés de buscar, como Strauss pretendia, uma fundamentação transcendente. Ao afirmar o político como autônomo e concreto, Schmitt estaria reproduzindo, na análise de Strauss, o argumento liberal da autonomia e da historicidade da cultura contra a natureza, ou seja, Schmitt estaria ainda vinculado ao liberalismo, também por esta via, no que Strauss lamenta que “a proposição 'o político precede o Estado' não representa uma verdade eterna, mas sim uma verdade presente" (STRAUSS, 2007, p. 99). Além disso, Schmitt não teria percebido que para elaborar uma frente contra o liberalismo teria que sustentar-se fora do terreno da cultura ao invés de buscar uma contradição no seu interior, ou seja, propor um retorno ou um além do liberalismo e não compreender "a questão da ordem das coisas humanas" (STRAUSS, 2007, p. 99) e, dessa forma, desconstruir o sistema racionalista liberal através de um momento constitutivo exterior ao liberalismo e não, simplesmente, antiliberal, tal como fizera com o argumento da decisão sobre a exceção e, no texto em questão, com a relação de antagonismo. Assim, Strauss aponta que, apesar da ambiguidade que o critério do político implica, qual seja, a questão de que o político seja apenas mais uma instância da cultura (Kulturprovinz), é possível admiti-lo como instância principal, ainda que localizada no interior do liberalismo e, desencadeia um ruptura no interior do status civilis, isto é, uma quebra da cultura. A separação entre cultura e natureza, mais precisamente, a noção de autonomia da cultura é o ponto em questão na análise straussiana,

[e]sse ponto de vista nos faz esquecer que 'cultura' sempre pressupõe algo que é cultivado: a cultura é sempre cultura da natureza [...] ela desenvolve as predisposições naturais; é o cuidado esmerado da natureza - não importa se da terra ou do espírito humano - e obedece, assim, às ordens que a natureza mesma dá. (STRAUSS, 2007, p. 104)

O sentido da cultura seria cuidar da natureza, cultivá-la uma vez que a natureza seria a medida do homem ${ }^{5}$. Todavia, a modernidade,

\footnotetext{
${ }^{5}$ Compreensão de Strauss sobre cultura é desenvolvida em outro texto do autor. No livro sobre Spinoza, ele afirma que "o objetivo da filosofia é a cultura, a cultura da natureza. O que a natureza oferece ao homem sem a atividade suplementar do próprio homem é suficiente apenas para uma vida de penúria. De modo que, para a vida se tornar mais confortável, o esforço humano é requisitado, bem como a ordenação da natureza desordenada. A cultura não introduz na natureza humana nenhuma ordem alheia à natureza, mas segue as linhas do interior da natureza. A cultura faz regularmente o que a natureza faz
} 
sobretudo com Hobbes, empreende uma luta contra a natureza e, ao concebê-la sem ordem e violenta, abandona-a como irracional e passa a "conceber a cultura como criação soberana do espírito quando se pressupõe a natureza cultivada como oposta ao espírito e quando ela é esquecida" (STRAUSS, 2007, p. 105). Este esquecimento da natureza que Strauss ressalta na modernidade, sobretudo do conflito e da morte como possibilidade aberta, é a condição original ou o status naturalis fundamental do homem. Desta perspectiva, Strauss reconhece a importância do argumento do político schmittiano em recolocar o status naturalis como fundamento da ordem liberal. No entanto, a questão é que Strauss desloca demais o sentido do político ou do status naturalis em jogo no Der Begriff des Politischen: para Schmitt, não está em questão uma natureza anterior, uma vez que ele localiza no interior da vida civil a relação de conflito. Strauss, porém, concorda com a quebra da autonomia da cultura (sociedade) e na necessidade de pensar uma condição ou pressuposto político para o liberalismo (autodeclarado apolítico ou antipolítico), porém que não se fundasse em algum âmbito da cultura: no caso de Schmitt, como relação e antagonismo que não rejeita a violência (daí decorre a acusação de irracionalidade para alguns e o retorno da natureza no interior do status civilis), esboçando um existencialismo político como alternativa precária, mas válida diante do normativismo; no caso de Strauss, uma ordem natural a orientar a vida civil, mas que dela não faça parte, retornando para uma concepção antiga de teoria política. Aqui a distinção radical entre os conservadores em sua recusa do liberalismo: Schmitt insiste no momento constitutivo marcado pelo conflito anterior à norma ou à racionalidade liberal, ou seja, o liberalismo até nega o político, mas não elimina sua existência concreta, tornando-se mais uma ocorrência do politico; na leitura de Strauss, como a cultura é sempre cultura da natureza, proveniente dela, não faz sentido permanecer no interior da cultura, mesmo demonstrando o momento constitutivo do status naturalis ${ }^{6}$.

esporádica e casualmente. A cultura é fundamentalmente método, apenas método." (STRAUSS, 1997, p. 90).

${ }^{6}$ Neste aspecto é relevante uma distinção elaborada por Quentin Skinner (1996) sobre a via antigua (a partir dos teóricos baseados em Agostinho e Tomás de Aquino e a via moderna, sobretudo com Ockham e os humanista do Renascimento: enquanto a via antiga refere-se à lei natural segundo a qual as sociedades devem se constituir; a via moderna, ao contrário, prescinde do fundamento natural e afirma as relações políticas na cidade. Segundo SKINNER (1996, p. 421), "Outro grupo de humanistas, a quem os teóricos da Contra Reforma ansiavam ainda mais por combater, eram os defensores da ragoine di stato, em especial Maquiavel (...) identificaram com muita clareza o ponto central para o qual se podia afirmar que convergiam as teoria políticas de Lutero e Maquiavel: ambos se empenhavam, ainda que por motivos bem diferentes, em rejeitar a ideia da lei natural enquanto base moral adequada para a vida política". Em outro trecho, Skinner afirma que os tomistas desenvolveram uma teoria da sociedade política em oposição aos hereges, afastaram-se da escolástica (concebida por Ockham) e "recorreram à tese fundamental da via antiga, segundo a qual o homem tem a capacidade de usar seu raciocínio para criar os 
Em relação ao conceito de cultura, para Strauss, significa "a totalidade do pensamento e da ação dos homens que se organizam em domínios diversos e relativamente autônomos, em províncias de cultura [Natorp]" (STRAUSS, 2007, p. 102). Neste contexto, é a permanência neste nível cultural e histórico que a crítica straussiana aponta, pois "Schmitt permaneceria no horizonte desta resposta" (STRAUSS, 2007, p. 102). Todavia, Strauss reconhece que, apesar da solução imanente de Schmitt, é possível retirar a ambiguidade do político em relação a outras províncias da cultura: "a distinção entre amigos-inimigos 'não é de igual valor ou análoga àquelas outras distinções; o político não constitui 'um novo domínio concreto particular"' (STRAUSS, 2007, p. 102). Leitor atento, Strauss percebe que Schmitt passa a apostar na imanência como estratégia contra o liberalismo, embora discorde da ação em meio às relações humanas e priorize a questão da natureza ou, mais propriamente, a postulação de uma metafísica política. Assim, esta segunda crítica colhida do texto de Strauss já revela, ou melhor, antecipa nem tanto uma interpretação, mas sim um desejo de orientação metafísica que gostaria que Schmitt tomasse. Neste contexto, faz sentido a crítica à imanentização, já tornada lugar comum por outros intérpretes de Schmitt, por exemplo, desde Erik Voegelin (2001) até Roberto Esposito (1999). Logo no §1 das Anmerkungen, Strauss reconhece que o campo de investigação schmittiano é o do "human things" ou ainda quando afirma que "Schmitt só pretende conhecer o que é" (STRAUSS, 2007, p. 108): o retorno do político para Schmitt dá-se na relação humana do conflito ao invés da procura metafísica de algum fundamento ou substância. Apesar desta diferença, Strauss reconhece que Schmitt tenha conseguido contrariar os avanços liberais mesmo permanecendo no seu interior, ou seja, na interpretação de Strauss, o conceito do político schmittiano se apresenta como o fundamento da cultura na posição de um status naturalis interno, isto é, um estado de conflito e, ao menos, "a partir da possibilidade da guerra (caso extremo) a vida adquire sua função especificamente política" (STRAUSS, 2007, p. 108). Não obstante, Strauss sustenta que Schmitt enfraquece seu argumento, pois ainda articulado com as polarizações próprias do âmbito da cultura e, sobretudo, ao referir-se às

alicerces morais da vida política" (SKINNER, 1996, p. 425). A teoria da lei natural, como rejeição da via moderna (finitista) dá autoridade às leis a partir da adequação com os teoremas da justiça natural, de forma que "para que as leis positivas criadas pelos homens assumam o caráter e autoridade de leis genuínas, devem ser compatíveis, em todo os momentos, com os teoremas da justiça natural propostos pelas leis da natureza. Assim esta última fornece uma estrutura moral dentro da qual devem operar todas as leis humanas; inversamente, o objetivo dessas leis humanas consiste apenas em fazer vigir, no mundo (in foro externo), uma lei superior que todo homem já conhece em sua consciência (in foro interno)" (SKINNER, 1996, p. 426). A via antiga se sobrepõe através de Suárez e dos Contratualistas aos teóricos da via moderna. Neste texto sobre o político, Schmitt estaria próximo aos teóricos da via moderna; Strauss, da via antiga. 
aspirações liberais de autonomia, gera a ambiguidade já referida no conceito do político, mesmo considerando que a possibilidade da guerra não é apenas "o caso extremo dentro de um âmbito autônomo, mas é o caso extremo por antonomásia para o ser humano, já que se refere à possibilidade real da eliminação física e a mantém latente" (STRAUSS, 2007, p. 104) e, por isso, o político "não é um domínio concreto, relativamente autônomo, entre outros. (...) não é de igual valor nem análogo ao moral, o estético, o econômico, etc." (STRAUSS, 2007, p. 104), mas demonstra que o político é fundamental para as outras esferas, mesmo que dentro da finitude. Dessa forma, até mesmo Strauss assume que Schmitt critica a autonomia dos diversos domínios concretos do pensamento e da ação humana, revelando a originariedade do político, isto é, do conflito diante dos âmbitos culturais. Apesar do restabelecimento da noção de um status naturalis, este ainda ocorreria no interior da cultura, desfeito o vínculo com uma compreensão anterior de natureza ou ideal da justiça e da ordem e, por conseguinte, aprofundando-se na fundação liberal da política moderna. Esta segunda crítica aberta num dos flancos da teoria schmittiana pode tanto quanto a primeira suscitar réplica, como a seguinte: ao criticar a localização do político schmittiano no mundo da cultura, isto é, no terreno liberal, mesmo relativizando a autonomia das "províncias de cultura", Strauss aposta numa localização não liberal da política, num retorno à natureza, como algo perdido e autêntico. Em todo caso, desperta a possibilidade não apenas de uma compreensão do político como status do homem como também a possibilidade de uma política pós-liberal que em Schmitt poderia ser pensada sem apelar para algum aspecto fundacional (metafísico), pois o político apenas compreende a finitude das relações humanas.

Na luta contra o Estado empreendida pelo liberalismo, Schmitt percebe o retorno do político como conflito na própria compreensão liberal que se autodeclara antipolítica (ou apolítica, em todo caso, pacífica, não violenta, contra o conflito, técnica, etc.). Apesar do malabarismo de afirmar que a despolitização polemicamente expressa, mal disfarçado, seu sentido político, Schmitt arrola mais um argumento para desconstruir as fileiras liberais: até mesmo o pacifismo ou o discurso técnico-econômico traz consigo a marca do político, salvaguardando a persistência do político como contradição e conflito no interior da hegemonia liberal. As novas associações e formas sociais que reivindicam o fim do Estado teriam nesta reivindicação um papel político e, dessa forma, apenas confirmariam a existência do conflito, os movimento de neutralização e despolitização, pois, a partir disso, Schmitt afirma a autonomia e a inescapabilidade (necessidade) do político. Entretanto, na perspectiva de Strauss, no que consiste em seu terceiro argumento crítico, as teses de Schmitt se enredam, mais uma vez, no liberalismo: em primeiro lugar, ele não conseguiria demonstrar a existência permanente (a partir de considerações fáticas e históricas, como pretende) do político: um mundo pacificado e sem conflitos 
é uma possibilidade que, apesar de improvável, pode vir a existir. Então, em segundo lugar, Strauss avança, sustentando que as considerações de Schmitt recuam para uma "profissão de fé antropológica", segundo a qual o político seria real e necessário por conta da natureza humana marcada pelo perigo (Gefährlichkeit): "a oposição entre a negação e a afirmação do político se remonta a um debate sobre a natureza humana (...) se o homem é bom ou mal por natureza (...) a hipótese da periculosidade humana é, portanto, o suposto último do político" (STRAUSS, 2007, p. 111). Assim, em terceiro lugar, a leitura do filósofo aponta, curiosamente, que a afirmação do político como conflito é, na verdade, uma afirmação moral, ou seja, mesmo assumindo a periculosidade do homem, este pressuposto antropológico seria, como o próprio jurista reconhece, uma "fé", uma vez que não estaria demonstrada sua necessidade lógica. Strauss aponta esta limitação, além do nexo entre a natureza humana e o político ao afirmar que "tão verdadeira quanto a periculosidade do homem, também a necessidade do político, ambas se sustentam (...) se a periculosidade do homem é apenas crível, então se encontra também ameaçada (...) o político" (STRAUSS, 2007, p. 111). Assim, o político não se sustenta, a não ser lançando mão de um argumento moral contra o liberalismo, qual seja, a afirmação da superioridade da vida do conflito diante da segurança burguesa: caso haja a extinção dos antagonismos, Schmitt teria que se respaldar em outro pressuposto, conforme Strauss:

se, em última instância, o político está ameaçado, então a afirmação do político deve ir mais além do reconhecimento da sua realidade: deve intervir de maneira ativa em favor do político ameaçado, deve afirmar o político. Isto nos leva a perguntar necessariamente: por que Schmitt afirma o político? (STRAUSS, 2007, p. 112).

No entanto, parece que Strauss comete um equívoco ao deduzir uma moral a partir de uma afirmação de estados de coisas. Além disso, utiliza um salto injustificável no raciocínio sobre o político: um "deve" que é interpretado como um imperativo categórico político ao invés de mera descrição própria de um realismo ou finitismo político. Embora o argumento não seja tão simples de desembaraçar, o autor mesmo prossegue por uma via contraditória. Se, ao elogiar em Schmitt, parafraseando-o, assume como proposição válida, a tese de que "o político não tem nenhum sentido normativo, mas sim existencial” (STRAUSS, 2007, p. 112), não seria contraditório pressupor uma afirmação moral (no sentido de um valor transcendente) a um sentido concreto? Ou bem denunciaria o pressuposto escondido por Schmitt e desmancharia o conceito do político, ou bem, ao guardar as duas proposições como válidas, assume uma contradição: uma teoria que qualifica ora como imanentista (monista) ora como dualista, com primazia da moral, o que parece enfraquecer suas análises. No entanto, 
Strauss parece não se intimidar com a contradição, por exemplo, quando sustenta que "a afirmação da periculosidade não tem um sentido político (leia-se existencial), mas sim apenas um sentido normativo, moral (...) é a afirmação da força como força criadora de estados, da virtude no sentido maquiavélico" (STRAUSS, 2007, p. 112). Uma contradição que, porém, Schmitt parece se esquivar de cometer se sua teoria política for compreendida como um finitismo e a necessidade do político como um estado de coisas ou como uma condição e a priori histórico, para usar uma expressão estranha ao autor, mas que neste caso é apropriada. Para Strauss, Schmitt deveria ou bem reconhecer o político como contingente - pois carente do atributo de necessidade - o que não seria admitido por um filósofo marcado mais por um realismo metafísico do que por um realismo político, ou bem não afirmar o político como necessário ou inescapável, pois, dessa forma, evidencia-se que a afirmação seria uma proteção "porque sua condição de ameaçado vê ameaça à seriedade da vida humana" (STRAUSS, 2007, p. 117), uma postura moral que Strauss denuncia como fundamento do político.

Apesar das ressalvas, Strauss reconhece o político como aquilo que dota a vida humana de seriedade. No entanto, mais uma vez, desenvolve uma consideração sutil em sua análise sobre o texto em questão: embora Schmitt proponha, na esteira de Hobbes, o sacrifício das vidas (a possibilidade da morte) e a iminência do conflito como critérios do político, ou seja, um resgate da condição natural do homem dentro do projeto liberal falido; a tendência social no liberalismo, segundo Strauss, possui fins não políticos, tais como, ciência, tecnologia, comércio, etc., e não teria, portanto, como compreender este critério. Assim, para Strauss, a institucionalização da política moderna provocou o abandono da natureza e dos afetos em direção à racionalidade da cultura e da civilização com o consequente esquecimento do raciocínio político de base a partir do qual se deu a associação dos indivíduos: o medo sofreu uma institucionalização suficientemente forte para tornar a "eventualidade do conflito" algo não presente no cotidiano. Numa palavra, a ação e o pensamento não são regrados a partir da eventualidade do conflito, pois a cultura ou o mundo liberal orientam-se fora desta hipótese. O Estado subalterno à sociedade seria, conforme Strauss, o destino daquela hipótese lançada por Hobbes. Este teria lançado "os fundamentos do liberalismo para contrapor-se à natureza não liberal do homem" (STRAUSS, 2007, p. 107). Assim, a percepção do perigo iminente, natureza irracional do conflito, não estaria mais acessível ao indivíduo liberal, pois:

desconhece seus próprios pressupostos e metas, confiam na bondade original (fundadas na criação e providência divinas) da natureza humana; ou, amparando-se na (suposta) neutralidade das ciências naturais, nutrem esperança de um aperfeiçoamento da natureza humana, em vista da qual a 
experiência que os homens têm de si mesmo não fornecem nenhuma justificação (STRAUSS, 2007, p. 107).

Segundo Strauss, Hobbes lutou contra a natureza não liberal do homem ao inaugurar o processo de neutralização (da religião e das guerras civis religiosas) e construir uma estabilização da ordem desencadeando um processo lógico no qual assume a técnica como método para a supressão do estado de natureza e alcance da segurança e paz. Em termos schmittianos, que faz análise semelhante, a legislatur humanus torna-se uma machina legislatorium que, como máquina, possui em si a justiça e a verdade como seu próprio funcionamento, abrindo espaço para a tolerância religiosa e a legalidade pacifista, numa palavra, a consciência individual. Neste caso, Strauss mais uma vez adota a critica de Schmitt à obrigação apenas in foro externo que franqueia o espaço privado para "a liberdade de pensamento e da consciência" (Gedanken und Gewissensfreiheit), inclusive, a admissão legal de grupos contrários ao poder estatal. Desta fissura entre público e privado que, conforme a leitura de Strauss, o mundo liberal se esquece, advém o perigo de onde foi criado (cultura da natureza), além de, inadvertidamente, acreditar na bondade do indivíduo, na autodeterminação do sujeito e, por conseguinte, na negação do Estado, uma vez que apenas a afirmação não liberal da periculosidade pode garantir a necessidade de governo. Assim, propriedade privada, livre-consciência, liberdade contra o Estado e até mesmo democracia (representativa) são conceitos políticos escamoteados como afeto antiestatal peculiar do liberalismo. Para Schmitt, um afeto polêmico que, apesar de se declarar antipolítico - porque antiestatal, nesse monopólio ou hegemonia provisória do Estado sobre o político - é ele mesmo político. Neste ponto, um comentário importante de Strauss, qual seja, diante da percepção de que a ciência moderna solapou suas próprias bases originais, na verdade, sem sua base política, pois ausente a orientação da vida humana ao conflito, Strauss confirma a leitura de Schmitt, segundo a qual, no mundo liberal esquece-se a natureza hostil que se contrapõe à civilização com o sacrifício dos afetos e institucionalização da vida política. A ação política, isto é, orientada pela eventualidade do conflito não é mais levada em conta nas associações liberais, pois a natureza não liberal do homem, isto é, o status naturalis ou a relação como conflito foram esquecidos. Assim, contra a vida tecnicizada, Strauss reforça a visão schmittiana do conflito, por mais que considere precisamente por aí sua impossibilidade, uma vez que teria que realizar a crítica para além do solo liberal, pois o sacrifício da vida e o conflito não têm mais espaço numa concepção de mundo liberal na qual os fins sociais não se orientam pela política, mas sim pela tecnologia, ciência, economia e resolução de conflitos, entre outros dispositivos. Para Strauss, apenas uma crítica externa ao mundo liberal é capaz de elaborar um diagnóstico da época. No entanto, enquanto Strauss propõe o retorno aos antigos, criticando a argumentação "liberal" de Schmitt; o jurista elege precisamente o mundo liberal para 
realocar esta irracionalidade ou estado de natureza: ele demonstra que na origem sempre presente do mundo liberal há conflito e irracionalidade. Mesmo assim, Strauss põe em marcha uma crítica da filosofia da cultura (Kulturphilosophie) como crítica ao liberalismo procurando uma força centrífuga: crítica à tolerância e liberdade do indivíduo contra a moral inscrita na natureza; em última instância, ele critica a modernidade e sua forma política, o liberalismo, por fixar-se na compreensão das coisas humanas ou da cultura e civilização e esquecer-se que a verdade está como antigos observam - na natureza. Assim, arremata a análise deste argumento contra Schmitt, apontando ainda para Hobbes: a ausência do questionamento sobre a melhor ordem política e, por isso, a falta de orientação moral à sociedade que leva, por conseguinte, à dissolução e ao rebaixamento moral do liberalismo. Strauss afirma que:

\begin{abstract}
se é verdade que a autoconsciência definitiva do liberalismo é a filosofia da cultura, podemos concluir que o liberalismo, envolvido e absorto na segurança do mundo da cultura, esquece a fundação da cultura, o estado de natureza, isto é, a natureza humana na sua periculosidade (Gefählichkeit) e no seu estar em perigo (Gefährdetheit) (STRAUSS, 2007, p. 108).
\end{abstract}

Em vista da última nota acerca do conceito do político, o filósofo complementa, no quinto argumento colhido em seus comentários, que, embora haja ambiguidade na relação entre cultura e o político, nenhum âmbito da cultura dá conta da morte física, tal como o político. O conflito e a possibilidade da morte é o meio pelo qual Schmitt evita que o mundocultura torne-se mero entretenimento, conservando a seriedade da vida e instalando permanentemente não o medo, mas o conflito. Daí, em parte, Schmitt consegue se desvencilhar de Hobbes (o medo em Hobbes é individual, o conflito em Schmitt é coletivo, público, pois - como sustentamos - Schmitt não funda a política no afeto do medo, mas no de conflito, ou mais precisamente, no antagonismo). Ele afirma o político, descrevendo a seriedade da vida posta diante do conflito, contra a negação liberal, isto é, a vida orientada para o consumo e homogeneidade enquanto mero jogo. Para Strauss, como já exposto, esta afirmação teria uma motivação moral, ou melhor, uma escolha sobre a superioridade da relação política sobre a proposta pelo liberalismo. Não obstante, Strauss encontra em Schmitt um aliado para rechaçar a civilização liberal diante da sua decadência na década de 1920, por considerar o consumo e o conforto da técnica como finis ultimus do liberalismo, ou seja, a renúncia liberal sobre os fins e ênfase nos meios (tecnologias), tal como Strauss considera:

em um mundo não liberal, Hobbes lança os fundamentos do liberalismo para contrapor-se à natureza 'não liberal' - com o perdão da palavra - do homem. Os homens de épocas posteriores, porém, que desconhecem seus próprios 
pressupostos (Voraussetzungen) e metas, confiam na bondade original (fundamentadas na criação e na providência divinas) da natureza humana; ou, amparando-se na (suposta) neutralidade das ciências naturais, nutrem esperança de um aperfeiçoamento (Verbesserung) da natureza humana, em vista da qual a experiência que os homens têm de si mesmo não fornece nenhuma justificação (STRAUSS, 2007, p. 107).

O finis ultimus se transforma em frivolidade: "levam ao ideal de civilização, isto é, à prescrição de relações sociais racionais da humanidade como uma "parceria no consumo e na produção"' (STRAUSS, 2007, p. 107). Para Strauss, Schmitt ainda aqui não consegue se desembaraçar do liberalismo, pois mesmo ao sustentar a maldade natural do homem entendida como periculosidade da natureza humana e assim garantir o domínio pelo Estado - este argumento seria fundamentalmente moral: "Schmitt afirma o político, pois enxerga no status ameaçado do político uma ameaça à seriedade da vida humana" (STRAUSS, 2007, p. 117). Como a cultura não justifica o sacrifício ou a possibilidade da morte, uma vez que se refere à natureza, ela perdeu o status naturalis e a possibilidade de compreendê-la tendo por base a relação do conflito, logo marcada como irracional. Para Schmitt, segundo Strauss, esta seria a crise do liberalismo: não consegue dar conta do Ernstfall por meio de considerações puramente econômicas, morais, culturais, entre outras e, por conta deste esquecimento imperdoável da natureza, dá-se o motivo da crise da civilização que Schmitt tentaria resgatar através da figura do status naturalis como conflito e luta efetiva a partir da existência real do inimigo, do perspectivismo e de uma identidade que não se confunde com identidade cultural, embora diante dela encontre um pouco de dificuldade para se distanciar. Na leitura de Strauss, portanto, ao afirmar a periculosidade humana como pressuposto do político, Schmitt não conseguiria sustentar o caráter inescapável (necessário) do político - para o político existir, seria necessária a permanência de uma oposição, mas a questão é que esta permanência não pode ser garantida com um critério metafísico em Schmitt - porém, ao menos, devolve ao mundo burguês a seriedade ao invés da frivolidade do consumo.

A leitura de Strauss pode indicar alguns ganhos conceituais na interpretação do Der Begriff des Politischen: apesar de reconhecer a possibilidade da ausência de conflitos, o político como conflito apenas expressa a negatividade como condição histórica para a ação política, sem a necessidade de uma "profissão de fé antropológica" ou a necessidade de um raciocínio teológico. Daí, a interpretação de Strauss segundo a qual a afirmação da maldade ou da periculosidade do homem (em última instância a afirmação do político) seria uma afirmação da moral aparece com uma tentativa de dotar o conceito do político de um fundamento ou elemento transcendente. Strauss ainda apresenta mais uma análise das consequências do conceito do político. Para ele, tomar a Gefählichkeit como pressuposto 
do político significa assumir uma configuração de forças sempre em oposição. Caso não ocorra, o político seria extinto. Este argumento straussiano, mais uma vez, deseja e projeta mais do que interpreta: a pretensão de uma unidade ou instância ideal no qual os conflitos fossem solucionados ou, pelo menos, houvesse uma resolução fora da imanência das relações. Entretanto, a principal crítica presente na leitura de Strauss seria, na verdade, a de que o autor do Der Begriff des Politischen põe a questão política da dominação estatal sob uma consideração moral: a periculosidade ou maldade do homem seria o critério do político. A partir daí, Strauss entra novamente em contradição na leitura: afirma, por um lado, que Schmitt trata das coisas humanas, mas por outro, interpreta que o jurista almeja o conhecimento puro e completo por meio do político uma vez que afirma ser a questão fundamental do Estado ou da política o problema do bem e do mal, lidas como maldade ou periculosidade humana e ordem estatal e soberana.

Numa sexta crítica presente em suas Notas, Strauss dirige uma crítica conformada à Schmitt ao descrevê-lo como imanentista, mais precisamente, ao acusá-lo de abandonar a Veritas transcendente e fixar-se nas "coisas humanas". Este argumento é importante para a confirmação de alguns aspectos da tese que sustentamos acerca do finitismo em Schmitt e gostaríamos de retomá-lo neste parágrafo, justamente numa análise de caráter metafísico como a de Strauss. Tanto em Schmitt quanto em Strauss, a consequência mais nociva do liberalismo é o individualismo, ou melhor, o modo de vida baseado no esvaziamento e substituição do sentido da existência pela segurança e paz, mera satisfação das paixões ou necessidades individuais que culminam na despolitização. Para ambos, o político como relação de conflito e o eventual sacrifício das vidas, garante que o mundo não seja apenas consumo ou entretenimento, pois dá à vida humana alguma dignidade ou solenidade, num retorno ou nostalgia, em um autor evidente; em outro, hesitante, às teses antigas. Apesar de considerar a afirmação do político como uma afirmação moral, como demonstrado anteriormente, Strauss reconhece a importância da escolha pelo caso sério ou extremo (Ernstfall) contra o liberalismo que despolitiza os conflitos e os transforma em jogos ou competições, no final das contas, em entretenimento e ausência de sentido. Se, para Schmitt, todavia, a perda da seriedade é a negação do político, já que sustenta que nenhum âmbito da vida é capaz de dar conta da morte física do indivíduo; de certa forma, a negação do político é um ataque à centralidade do Estado que possuiria, na modernidade, o monopólio histórico do político, daí a importância da afirmação do político; para Strauss, entretanto, o liberalismo significa, desde Hobbes, a ausência do questionamento sobre a melhor ordem política, que deveria ser recuperada por um conceito de político (ou de filosofia política) voltado às origens. E esta é a crítica que mais uma vez é dirigida à Schmitt: o jurista permanece na imanência e, por isso, segundo Strauss, Schmitt não se refere 
à verdade eterna, fundamento do político, restando-lhe a contingência da instância histórica, de onde não é possível pensar a melhor ordem política. Por conta do abandono da Veritas, Schmitt deixa de resolver a tensão entre amigos e inimigos (entendida de maneira maniqueísta como mera afirmação de um dos polos e não, como propomos, como relação e antagonismo), pois a oposição não se refere a uma instância ideal ou abstrata capaz de solucionar como uma unidade o problema do político e permanece na negatividade. Esta ausência de transcendência é motivo de lamentação para o platônico Strauss. Ele expressa numa fórmula que vale pela lucidez quanto aos objetivos de Schmitt em Der Begriff des Politischen: "O tratado de Schmitt aborda a questão da ordem das coisas humanas" (STRAUSS, 2007, p. 99). Para Strauss, como o liberalismo rejeita a possibilidade de uma moral vinculada à natureza, as ações humanas careceriam de uma orientação moral, porém Schmitt cairia no mesmo equívoco: além de escamotear uma moral na afirmação do político, mesmo sem vincular-se a alguma ordem natural ou metafísica, ele não teria se livrado do âmbito da cultura. Interessante que Strauss acusa a falta de orientação moral e projeta esta falta para Schmitt quando sustenta que a afirmação do político possui uma carga moral, ou melhor, um pressuposto moral de Schmitt, como mera preferência, contra a despolitização e neutralização do liberalismo. A tentativa de Schmitt é, todavia, apenas tornar contíguo status naturalis e status civilis, mais precisamente, a manutenção do inimigo (relação e antagonismo) no interior da ordem como uma stasis ou guerra civil que apenas o Estado poderia controlar e, dessa forma, contrapondo-se à negação liberal do Estado, uma vez que estaria incapacitado de dar conta da violência originária da ordem. Vê-se, por um lado, Hobbes com o argumento do medo da morte e a pretensão de desdobrá-lo na extinção dos afetos não racionais diante da estabilização da ordem com segurança e paz: racional, portanto, nos efeitos, mesmo à custa do caso extremo; por outro, Schmitt, como admirado em parte por Strauss, mantém este caso sério no interior da ordem, incrustando a relação de conflito em um reestabelecido 'lugar de honra', isto é, no status naturalis como fundamento da cultura, bem como o político como status fundamental e extremo do homem. Strauss constata que Schmitt permanece na imanência e, sem analisar o mérito da sua leitura, encontra-se a primeira confirmação da perspectiva finitista e pluralista na obra do jurista.

No sétimo comentário relevante para nossa pesquisa, numa formulação já bastante conhecida, Strauss argumenta que Schmitt teria um "liberalismo com sinal trocado" (STRAUSS, 2007, p. 120). Strauss acusa a ausência substancial do conceito do político, que teria tolerância com qualquer tipo de postura ou conteúdo desde que se agrupasse em conflito. Como não há outro critério que não seja o conflito para tratar acerca do "problema indelimitável" do político, não haveria também um conteúdo próprio ou temas a priori políticos. A questão, porém, é justamente esta: 
Schmitt não propõe conteúdo ou valores nem escolhe um dos polos, mas apenas resgata a luta como lugar único possível do político, isto é, da seriedade e, portanto, da vida. Assim, Schmitt, sem a preferência moral pelo político, teria que sustentar que o "ser-político significa estar orientado para o 'caso extremo'. Por isso, afirmar o político é afirmar a luta enquanto tal, sem que importe em nome de que se luta" (STRAUSS, 2007, p. 127), e, dessa forma, a partir desta postura neutra quanto aos motivos do conflito, Schmitt:

respeita todos os que querem lutar; é tão tolerante como os liberais, só que com a intenção oposta: enquanto o liberal respeita e tolera todas as convicções "honestas" (...) ordem legal e a paz, o que afirma o político respeita e tolera todas as convicções "sérias", isto é, todas as decisões orientadas para a possibilidade real da guerra. A afirmação do político se revela como um liberalismo de sinal contrário. (STRAUSS, 2007, p. 120)

Para Strauss, Schmitt não apenas se move conceitualmente na perspectiva liberal - neste caso, assumindo um pluralismo ou diferença como condição do político, o que, em nossa perspectiva não o qualifica, sem mais, como liberal - mas também assumiria a neutralidade liberal: através do princípio da inescapabilidade ou da necessidade do político, ele respeita todos aqueles que querem lutar, mesmo que na luta não assumam uma bandeira ou coloração específica: não é negado o atributo de político àquele que assume o conflito. No entanto, a despeito de Strauss, pode-se compreender a estratégia de Schmitt como um perspectivismo típico: jogar contra o liberalismo sua pretensa neutralidade, isto é, a afirmação de neutralidade que expressa a realidade política do liberalismo, sua luta contra o político, afinal, é ela mesma política. Schmitt demonstra ainda que o discurso não político do liberalismo é, no final das contas, político e, dessa forma, nada escaparia da relação política. Ele seria tolerante assim como o liberal, porém pelo motivo oposto. Schmitt desdenha, por exemplo, do ideal de pacifismo declarado pelo liberalismo e sustenta, nas entrelinhas, uma tese pluralista ou perspectivista segundo a qual pressupõe a existência concreta do outro, fato ineliminável da teoria política. Strauss, porém, vê sob outra base este discurso e se não esconde sua fonte platônica na compreensão da relação política, pois "estamos sempre disputando como outro e com nos mesmos sobre o justo e o bom" (STRAUSS, 2007, p. 188). Para Strauss, nem o conflito nem o conforto, mas a excelência humana e conformidade com a natureza: se a seriedade está ligada ao conflito, este só pode se dar em direção ao justo. Em última instância, justifica o conflito, a separação e, inclusive, o sacrifício da vida, mas a partir da política como reflexão sobre a melhor ordem.

Não obstante, neste ponto, Strauss encontra em Schmitt uma referência, apesar do imanentismo, finitismo e pluralismo deste: há uma 
natureza ou periculosidade, algo irracional relativo àquele medo e violência que é preservado na cultura ou civilização. Strauss encontra um forte argumento, embora não desenvolvido, ao compreender o político como uma espécie de fundamentação não racional, ou melhor, afetiva da política. Retorna-se a um irracionalismo que caracteriza a fundação da cultura como estado de natureza, mais precisamente, como "periculosidade (Gefähllichkeit) e no seu estar em perigo (Gefährdetheit)" (STRAUSS, 2007, p. 108) e a solução estaria num retorno à natureza que Schmitt efetivou apenas parcialmente. Neste momento, Strauss concede o elogio de que Schmitt critica o liberalismo com a tese de que é necessário o retorno do status naturalis, anterior à cultura e ao amolecimento liberal, e o conceito do político como aquilo que é mais sério, fundamental e extremo, mesmo que lamente ainda o fato de que Schmitt não realoca este conflito fora da cultura, fora do mundo liberal ${ }^{7}$. Todavia, este argumento de Strauss parece uma interpretação contrária ao que Schmitt efetivamente faz: inserir no interior da ordem liberal o conflito. De certa forma, Schmitt executa um movimento oposto ao de Hobbes: insere a luta como irracional inextirpável, transforma a guerra civil em parâmetro e origem da sociedade burguesa. Método similar já tinha realizado no Politischen Theologie (SCHMITT, 2004): a exceção como constitutiva da ordem. No entanto, conforme a leitura que fazemos (e Strauss ao negá-la, confirma) em Der Begriff des Politischen não há uma ideia de ordem ou forma política a partir da qual a decisão se refere. Numa lúcida leitura, Strauss arremata: "o que [Schmitt] busca é excluir todas as possibilidades desse tipo [de juízo de valores]: o político não pode ser avaliado segundo valores, nem mediar-se conforme um ideal; aplicado ao político, todos ideais não são mais que 'abstrações', todas as abstrações normativas não são mais que "ficções"” (STRAUSS, 2007, p. 108-109). Assim, o político toma sua significação de sua relação permanente com a "possibilidade real de eliminação física dos homens" e, ainda segundo Strauss, para Schmitt "não existe um fim racional, nem uma norma justa, nem um ideal social tão belo, nem uma legalidade que possa fazer aparecer como algo justo que os homens se matem reciprocamente" (STRAUSS, 2007, p. 109). A seriedade da vida social implica o político como forma de vida oposta ao liberal: o que Strauss não enxerga, é que Schmitt expõe o conflito entre esses afetos diferentes, mas nem como mero pluralismo e tolerância política, nem como formas políticas ou estruturas normativas.

\footnotetext{
${ }^{7} \mathrm{Na}$ leitura de Meier, esta crítica de Strauss teria sido levada a sério por Schmitt ao ponto deste modificar nas edições seguintes do Der Begriff des Politischen a concepção do político como um domínio ou instância (relação social que ainda permaneceria no âmbito da cultura) para uma análise de fundamento ou estrutura última do político como intensidade. Esta passagem do critério do político de domínio ou instância para grau de intensidade teria sido provocada pela recepção das críticas dos comentários de Strauss. Cf. MEIER, 2006.
} 
A interpretação straussiana extrai a conclusão atípica de que Schmitt teria um liberalismo moral voltado ao conflito como resgate de um status naturalis que permitiria fundamentar a ordem a partir do bem. Inexplicável resultado exegético. $\mathrm{O}$ trecho citado por Strauss para fundamentar seu desfecho contraditório é "“a partir das forças de um saber íntegro" possa renascer "a ordem das coisas humanas"” (STRAUSS, 2007, p. 119) que interpreta como "a polêmica contra a moral - contra os ideais e as abstrações normativas - não o impedem de fazer um juízo moral sobre a moral humanitária" (STRAUSS, 2007, p. 119) e na tese de que Schmitt esforça-se em ocultar o juízo moral acerca do liberalismo. Na afirmação do político como um caráter inelutável, a ordem em Schmitt também seria não uma necessidade (falta-lhe o pressuposto essencialista que Strauss exige), mas uma afirmação moral da necessidade da ordem. Isto implica numa séria ameaça à tese do político, mas também uma possibilidade de compreensão não essencialista da sua teoria, mesmo, fenomenologicamente, sustentando a permanência do Estado e da ordem, ponto fraco em sua teoria que Strauss percebe. Neste contexto, Strauss finaliza as Anmerkungen com a pretensão de trazer Schmitt para suas fileiras: o jurista teria como objetivo o "saber íntegro" (e não o perspectivismo que o conceito do político implicaria), ou seja, "a origem não corrompida e não a natureza das coisas humanas" (STRAUSS, 2007, p. 122) e, além disso, Strauss remete o político para além da realidade e conflitos históricos: não vincula o bem e o justo à existência política concreta, mas sim ao conhecimento puro ou transcendente que ele mesmo tem em vista. Entre os dois conservadores, apesar de concordarem na crítica ao liberalismo, Schmitt aceita a ausência de transcendência, a impossibilidade do dualismo entre céu e terra e as consequências de uma época secularizada que transformaram o pensamento político, mesmo que ainda afirme a necessidade da ordem.

As críticas de Strauss, todavia, parecem surtir efeitos, embora não precisamente na direção apontada por Strauss: no início dos anos 1930, Schmitt propõe uma leitura mais coerente com o imanentismo do Der Begriff des Politischen: o institucionalismo ou pensamento da ordem concreta que mantém nas considerações acerca do texto sobre o Nomos, superando esta dualidade entre transcendência e imanência. A questão de Strauss, no entanto, serve para iluminar os próximos passos: realmente a "crítica ao liberalismo para consumar-se (...) deve ir para um horizonte para além do liberalismo" (STRAUSS, 2007, p. 122) e a partir desta consideração cabe uma última nota sobre o comentário de Strauss que corrobora a tese desta pesquisa: Schmitt hesita, mas se considerarmos a leitura de Strauss correta, qual seja, a ordem como algo não necessário pois Schmitt admite a imanência e, por conseguinte, a contingência da ordem - não é possível sustentar um Ziel ou instância transcendente. Em outras palavras, não há dualismo nem possibilidade de solução fora do político, mas - ainda concedendo méritos à leitura de Strauss - apenas uma 
afirmação moral sem transcendência. Dessa maneira, pode-se assumir o político - assim como o próprio liberalismo - e a ordem política como objetos possíveis ou contingentes, ou seja, Schmitt abre a possibilidade de pensar a política fora dos padrões fundacionais ou essencialistas da modernidade: como sua tese do político como finitismo ou imanentismo da relação de conflito, uma vez que a validade da ordem não é determinada por um critério certo e seguro sobre a melhor ordem ou forma política e o político mesmo é considerado in re, ou seja, lançado nos jogos da imanência; abre a possibilidade de elaboração de uma teoria pós-liberal, ou seja, o salto para fora do contexto liberal. Atualizamos o diagnóstico da leitura de Strauss e arriscamos completar os passos que seja Schmitt seja Strauss não desenvolveram: Strauss preocupa-se, como todo conservador da sua lavra, quanto à melhor ordem política e vê Schmitt, até então o teólogo da política, não se valer de verdade eterna, mas sim apenas da verdade história ou na sua estratégia de atacar por paradoxos, no caso, mais uma vez jogando com as armas do adversário liberal, segundo o argumento da neutralização. A preocupação de Strauss é que Schmitt se aprofunda com Hobbes na fundação modernidade política e, por isso, não escapa do paradigma liberal. Na verdade, a crítica de Strauss está correta na contradição de Schmitt em relação à Hobbes contra o liberalismo, mas equivocada quanto ao fato de que Schmitt prossiga no liberalismo. O que ele faz, se nos permitem um paralelismo descabido, é uma espécie de morte do liberalismo pelo próprio liberalismo: se Hobbes abre a modernidade, Schmitt encerra ou, ao menos, abre a possibilidade de se considerar outro paradigma político para além da modernidade, isto é, para além do liberalismo. Ele não apenas descarta a Veritas e assume a imanência ou a validade in re da ordem, mas aponta para outro tipo de teoria política não liberal ao fazer frente às teses políticas no terreno mesmo delas. Em todo caso, a crítica de Schmitt ao liberalismo tem, segundo Strauss, o mérito de reestabelecer o estado de natureza como fundamento da cultura e, sobretudo, o político como o estado fundamental do homem. Se Hobbes privilegiou o medo com o afeto constitutivo da ordem, Schmitt surge propondo novamente um afeto, no caso, o conflito, como afeto fundamental na constituição da ordem o que, por si, já daria ensejo outra percepção do político, não normativista nem racionalista que oblitera e sacrifica os afetos. Na leitura de Schmitt, reconhecida por Strauss, é o afeto de conflito ou do antagonismo e não uma norma ou princípio racional que determina a origem do político. A partir disso, seria possível pensar uma política para além do liberalismo. 


\section{Referências bibliográficas:}

STRAUSS, Leo. "Notes on Carl Schmitt, The Concept of the Political". In: SCHMITT, Carl. The Concept of the Political. Tradução de Matthias Konzen e John McCormick. Chicago: University of Chicago Press, 2007, p. 97-122.

Spinoza's Critique of Religion. Chicago: The University of Chicago Press, 1997.

SCHMITT, Carl. Der Begriff des Politischen. 6. Aufl. 5. Nachdruck der Ausgabe von 1963. Berlim: Duncker \& Humblot, 2002.

Politische Theologie. Vier Kapitel zur Lehre von der Souveränität, 8. Aufl. Berlim: Duncker \& Humblot, 2004.

ESPOSITO, Roberto. Categorie dell'impolitico. Bologna: Il Mulino, 1999.

MEIER, Heinrich. Carl Schmitt and Leo Strauss: the hidden dialogue. Chicago: The University of Chicago Press, 2006.

VOEGELIN, Erik. "Die Verfassungslehre von Carl Schmitt". In:

The Collected Works of Eric Voegelin, Volume 13: Selected Book Reviews. Jodi Cockerill; Barry Cooper, (Editores). Missouri: University of Missouri Press, 2001, p. 42-66. 